\title{
The impact of a national mass media campaign in The Netherlands on the prevention of weight gain
}

\author{
Birgitte Wammes ${ }^{1,2, *}$, Boudewijn Breedveld ${ }^{2}$, Caspar Looman $^{1}$ and Johannes Brug ${ }^{1}$ \\ 'Department of Public Health, Erasmus University Medical Center, PO Box 1738, 3000 DR Rotterdam, \\ The Netherlands: ${ }^{2}$ Netherlands Nutrition Centre Foundation, The Hague, The Netherlands
}

Submitted 1 November 2004: Accepted 10 May 2005

\begin{abstract}
Objective: A 5-year nationwide mass media campaign aimed at prevention of overweight was organised from 2002 onwards. The present study evaluates the first campaign, which was aimed primarily at increasing awareness of weight gain.

Design and subjects: Data were collected by telephone interview in four independent cross-sectional surveys among non-obese Dutch adults aged 25-35 years (total $n=1949$ ) for statistical analyses. Awareness of personal body-weight status, overweight-related risk perceptions, attitudes towards weight-gain prevention, motivation to prevent weight gain and self-reported body mass index (BMI) were measured in each survey. Campaign exposure was assessed in the post-intervention surveys. To identify intervention effects over time multiple linear and logistic regression analyses were used, adjusted for secular time effects and age.

Results: After the campaign about $65 \%$ of the respondents knew about the campaign. The campaign was associated with more positive attitudes towards the prevention of weight gain $(\beta=0.16 ; P<0.01)$ and higher self-reported BMI $(\beta=0.14 ; P<0.01)$. Conclusions: The results suggest that the first campaign reached a large proportion of the population and initiated some positive change in attitudes, but did not achieve significant improvements in other determinants of weight-gain prevention among non-obese young adults.
\end{abstract}

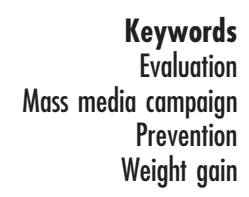

Evaluation

Prevention Weight gain
The proportion of people who can be classified as 'overweight' or 'obese' is increasing rapidly in Western countries ${ }^{1}$. Also in The Netherlands, the prevalence of obesity has roughly doubled over the last decade and now more than $40 \%$ of the Dutch adult population is overweight and more than $10 \%$ is obese . Overweight $^{2}$. and obesity are strongly related to cardiovascular diseases, diabetes, certain cancers and musculoskeletal disorders, and are expected to surpass tobacco as the most important determinant of preventable disease $\mathrm{e}^{3-5}$.

Prevention of gradual weight gain in early adulthood may be a key to arresting the overweight and obesity epidemic, since such weight gain is an important risk factor for overweight and obesity later in life ${ }^{6-8}$. However, there are indications that people are not actively trying to prevent weight gain, because they may not be aware of gradual weight gain, their body-weight status or their unhealthy eating and physical activity habits ${ }^{9-12}$. Further, gradual weight gain may be accepted as a 'fact of life' due to a lack of awareness that gaining an extra kilogram of weight each year eventually leads to health-threatening body weights ${ }^{13-15}$. Increased awareness is therefore regarded as an essential step in the prevention of weight gain.

In December 2002, the Netherlands Nutrition Centre (NNC), the organisation primarily responsible for nutrition education in The Netherlands, therefore decided to initiate a mass media campaign entitled 'Maak je Niet Dik!'* This campaign was to be the first of a 5-year initiative to promote preventive action on weight gain. The first phase of the 'Maak je Niet Dik!' campaign was aimed at placing the issue of weight-gain prevention on the public agenda, by creating awareness of a need to act (i.e. behaviour change) to prevent weight gain, and to induce more positive attitudes and intentions towards prevention of weight gain. The first campaign phase was explicitly targeted towards non-obese 'young adults' since the campaign was aimed at prevention of weight gain and not at weight loss, and because there is evidence that weight gain is most likely to occur between the ages of 25 and 34 years ${ }^{15,16}$. For prevention of weight gain relative small behavioural changes in physical activity and eating habits are sufficient. This is in contrast with behavioural changes necessary to achieve significant weight loss for treating obesity $^{17,18}$

As stated by Randolph and Viswanath' ${ }^{19}$, 'mass media campaigns are usually aimed at influencing the secular or normal trends in the amount of information available on a

*A literal translation of 'Maak je niet dik' is 'Don't get fat!' In Dutch, 'Maak je niet dik' is also a popular expression to say 'Don't worry'. 
given topic in a system'. This can be achieved by increasing the amount of information available on the topic of interest (e.g. number of newspaper stories, advertisements, printed material, etc.). To attract the attention of the target audience, campaign planners should attempt to redefine or frame the issue as a public health problem and suggest a solution to resolve it. Past experience has shown that the success of mass media campaigns has varied greatly. Different factors have been identified as important for the success of public health mass media campaigns. One such factor is that the audience has to be sufficiently exposed to the campaign messages and themes. Other conditions include using social marketing tools to create the appropriate messages for distribution, and using behaviour change theory to tailor messages to important mediators of behaviour change $\mathrm{e}^{20,21}$.

Mass media campaigns to promote healthy behaviours and discourage unhealthy behaviours have become a major tool to improve public health. In the past, mass media campaigns were often aimed at behaviour change, but with limited success. More recently, it has been recognised that media campaigns are less suited to initiate behaviour changes and should be more focused on influencing public and community agendas and influencing potential mediators of change such as risk awareness, attitudes or risk perceptions, i.e. to set the stage for social, behavioural and policy changes ${ }^{22-24}$. This means that, in evaluation of such campaigns, changes in such mediators should be monitored ${ }^{25}$ in order to improve the evidence base for the potential of media campaigns.

The present study therefore aimed to evaluate the first campaign phase of the NNC mass media campaign by investigating:

- the exposure of the target population to the campaign; and

- the effects of the campaign on awareness of personal weight status, attitudes and motivations towards the prevention of weight gain and risk perceptions of being overweight.

\section{Methods}

\section{The mass media campaign}

Mass media activities were conducted from 11 December 2002 until 9 February 2003. The messages to be communicated were developed to inform people about the fact that gaining an extra kilogram of excess body weight each year can lead to a health-compromising body weight; about the need for active prevention of weight gain by making relatively small and permanent changes in diet and physical activity; and to improve awareness of gradual weight gain and personal weight status.

The campaign included: (1) radio advertising (scheduled at intervals of two weeks, spanning 4 weeks);
(2) a brochure that included an easy-to-use body mass index (BMI) self-test and which came with a specially designed tape measure with self-explanatory indications to measure and evaluate waist circumference; (3) advertisements in daily newspapers and popular glossy magazines; (4) distribution of free cards; and (5) a website and a call centre where people could obtain further information. In the radio commercials and newspaper and journal advertising, consumers were referred to the website where they could check their body weight with a self-test and to the possibility to receive personal feedback about one's body weight on their mobile phone via text messaging. To increase distribution of the campaign materials, and to optimise information about the campaign, a mail shot was used with an information package to inform public health organisations in order to encourage them to help spread the campaign message. Campaign materials were pre-tested for acceptability of the message and content in a small research setting by means of qualitative testing. Furthermore, the campaign was advised by a steering group of representatives from national government, consumer affairs, nutrition education, the food industry and retailers.

\section{Distribution of the campaign materials}

Table 1 provides an overview of the distribution of the campaign materials. Most of the brochures with the waistline measures were distributed via intermediaries such as the public health organisations (79\%) and smaller numbers of people applied for the brochure via the Internet $(13 \%)$ or via text message on their mobile phone (3.5\%). After the start of the campaign, about 7500 people visited the website of the NNC per day for further information; this number was double the usual one. About a third of those who received personal feedback about their weight via a text message on their mobile phone received feedback that he or she was overweight.

Table 1 Quantity of campaign materials distributed and free campaign publicity during the intervention period

\begin{tabular}{lr}
\hline & Number \\
\hline Campaign materials/activities & 2294 \\
Radio commercials & 170500 \\
Brochures and waistline measures & 45 \\
Paid advertisements in daily newspapers and & \\
$\quad$ magazines & 240000 \\
Free cards & 39655 \\
Personal feedback via text message & \\
$\quad$ on mobile phones & 594 \\
Calls to telephone information number & 150000 \\
Website visits & 7 \\
Free publicity: information about the campaign on/in & 9 \\
Television & 23 \\
Radio & 6 \\
Newspapers & 12 \\
National magazines & 13 \\
Specialist journals & \\
Websites & \\
\hline
\end{tabular}


The start of the campaign regenerated a lot of free publicity. During the campaign period, the campaign was mentioned in total 76 times as news or information on television and radio programmes, in newspapers/ magazines/journals and on the Internet. The free publicity via television and radio was greatest in December, immediately after the start of the first campaign.

\section{Study design and sample}

Data were collected at four points in time via telephone surveys, of which two were conducted before the campaign in November and December 2002, and two were conducted after the campaign in January and February 2003. Respondents were selected by random sampling from telephone books by means of Random Digit Dialling. The interviews were conducted by trained interviewers and took about 15 min to complete.

The response rate for the four collection points varied from $66.8 \%$ to $79.1 \%$ (no significant difference between the response rates). When a potential respondent agreed to participate the interviewer asked about the inclusion criteria: being aged between 25 and 35 years; BMI between 20 and $30 \mathrm{~kg} \mathrm{~m}^{-2}$; not being pregnant. This resulted in a study population of 1949 'young' adults.

\section{Measures}

\section{Sociodemographic characteristics}

Demographic data included sex, age, weight, height, ethnicity, marital status and information on educational level. BMI $\left(\mathrm{kg} \mathrm{m}^{-2}\right)$ was calculated from the self-reported weight and height.

\section{Campaign exposure}

In the two surveys after the campaign was launched, campaign awareness was assessed in two ways. First, campaign recall was investigated by asking whether respondents knew about a campaign aimed at the prevention of overweight without further prompting. When respondents reported to know the campaign they were subsequently asked whether they knew the name of the campaign. When respondents did not recall the campaign, campaign recognition was then assessed by asking more explicitly if respondents knew about the campaign of the Netherlands Nutrition Centre called 'Maak je Niet Dik!' Respondents who recalled or recognised the campaign were then asked how they had heard about the campaign (i.e. television, radio, newspaper, brochure, Internet). Further, and in order to assess message recall, there respondents were asked in an open format whether they knew one of the messages of the campaign. Responses were subsequently categorised into five different categories. People either recalled messages related to 'watching your weight to prevent weight gain', 'healthy eating', 'being active', 'losing weight' and/or the 'increased prevalence of obesity'.

\section{Psychosocial variables}

Categorising respondents according to the congruence between their BMI and their self-rated weight status assessed awareness of personal body-weight status. Selfrated weight was measured by one item on a bipolar 5point scale, asking whether respondents rated their body weight as low or high ranging from 'far too light' $(-2)$ to 'far too heavy' $(+2)$. Respondents with BMI $>25 \mathrm{~kg} \mathrm{~m}^{-2}$ who rated their weight as not too high were classified as optimists; respondents with $\mathrm{BMI} \leq 25 \mathrm{~kg} \mathrm{~m}^{-2}$ who rated their weight as too high were classified as pessimists. All other respondents were classified as realists ${ }^{26}$. Attitudes towards the prevention of weight gain were assessed with three items on a bipolar 5-point scale ranging from 'very bad/unimportant/unpleasant' ( -2 ) to 'very good/important/pleasant' $(+2)$. Item scores were summed and divided by three to obtain a mean attitude score (Cronbach's $\alpha=0.53$ ). Risk perceptions of overweight were based on the perceived severity and vulnerability as defined by the Health Belief Model and Protection Motivation Theory ${ }^{27}$. Perceived severity was assessed by asking the respondents how bad they would think it was if they gained weight on a 3-point scale ranging from 'not bad at all' (1) to 'very bad' (3). Perceived vulnerability was assessed by asking respondents whether they believed they were less or more at risk for weight gain compared with others of approximately the same age and height on a bipolar 5-point scale ranging from 'much less at risk' (1) to 'much more at risk' (5). The multiplication of both item scores represented the risk perception score (range 1-15).

The stage of change from the Precaution Adoption Process Model $^{28}$ was used to assess the extent to which respondents were motivated to prevent weight gain. We asked respondents to choose one option out of five possibilities: (1) 'I have never thought about actively trying to prevent weight gain'; (2) 'I have thought about actively trying to prevent weight gain but I do not know yet whether I will do so'; (3) 'I have decided not to actively try to prevent weight gain'; (4) 'I have decided to actively try to prevent weight gain but I am currently not doing so (yet)'; (5) 'I do already actively try to prevent weight gain'. Respondents who chose option 1, 2 or 3 were categorised as unmotivated, and those who chose option 4 or 5 were categorised as being motivated to prevent weight gain.

\section{Statistical analysis}

Differences between the four independent surveys were first examined by comparisons, primarily to identify potential confounders, with two-tailed chi-square tests, analysis of variance or non-parametric tests (MannWhitney), dependent on the measurement level. $P$-values were set at $0.008(0.05 / 6)$ in order to correct for multiple testing. We used multiple logistic regression analyses 
(SPSS version 11.1; SPSS Inc., Chicago, IL, USA) to establish the predictive effects of demographic variables (sex, age, ethnicity, education, BMI) on the campaign awareness and message recall.

To investigate the predictive effect of the campaign on the awareness of personal body weight and motivation to actively prevent weight gain, multiple logistic regression analyses were carried out and linear regression analyses were used to investigate the impact of the campaign on attitudes towards the prevention of weight gain, risk perceptions of overweight and BMI. The dichotomous variable 'campaign' was the independent variable of primary interest and was created by coding the time period before the start of the campaign as 0 and the period after the campaign as 1.

Analyses were adjusted for secular time-trend effects (the changes in outcome measures over time which occur independently of the campaign) by inclusion of an extra independent variable in the regression model, which was defined as 'the number of weeks in time after the first pretest before the campaign'. Furthermore, interaction terms were included to investigate whether campaign effects differed for people who were overweight, women, lower educated and those of non-Dutch origin compared with normal-weight, men, higher educated and of non-Dutch origin. Differences were considered to be statistically significant if $P<0.05$.

\section{Results}

\section{Sociodemographic and psychosocial characteristics of the four surveys}

Table 2 shows the results of the four independent samples (pre- and post-tests). No differences in sociodemographic and psychosocial variables were found between the samples except that the mean age in the first pre-test was marginally higher compared with the first post-test.

In all samples the majority of respondents were aware of their weight status. Table 2 shows that these high levels of awareness remained constant in all campaign surveys. Risk perceptions of overweight were also constant, and a majority of the respondents perceived weight gain as serious, but only about one-third of the respondents perceived themselves as vulnerable for weight gain. Most respondents had positive attitudes and motivation to prevent weight gain, and the comparisons suggest more positive attitudes and a higher motivation after the first campaign.

\section{Campaign exposure}

Campaign awareness and message recall

More than half of the respondents (61\% in post-test 1; 66\% in post-test 2) were aware of the campaign, of whom 39.6\% (post-test 1) and 38.1\% (post-test 2) reported

Table 2 Description of the study samples: response rates and sociodemographic and psychosocial variables related to the prevention of weight gain at baseline (pre-tests) and after the intervention (post-tests) $(n=1949)$

\begin{tabular}{|c|c|c|c|c|c|}
\hline & \multicolumn{4}{|c|}{ Independent samples } & \multirow{3}{*}{$\begin{array}{c}\text { Significant } \\
\text { differences } \\
\text { between } \\
\text { the samples* }\end{array}$} \\
\hline & \multicolumn{2}{|c|}{ Pre-tests } & \multicolumn{2}{|c|}{ Post-tests } & \\
\hline & $1(n=486)$ & $2(n=493)$ & $3(n=487)$ & $4(n=483)$ & \\
\hline Response rate (\%) & 71.5 & 71.4 & 66.8 & 79.1 & - \\
\hline Sex, male (\%) & 45.3 & 44.6 & 40.9 & 42.7 & - \\
\hline Ethnicity, Dutch origin (\%) & 89.9 & 89.7 & 92.4 & 87.6 & - \\
\hline Education, higher educated (\%) & 52.3 & 49.7 & 48.3 & 55.8 & - \\
\hline $\mathrm{BMI}, \geq 25 \mathrm{~kg} \mathrm{~m}^{-2}(\%)$ & 31.1 & 28.5 & 33.5 & 30.4 & - \\
\hline \multicolumn{6}{|l|}{ Awareness of personal body weight (\%) } \\
\hline Realistic & 76.7 & 76.3 & 74.7 & 71.6 & - \\
\hline Optimistic & 6.0 & 6.5 & 5.5 & 6.8 & - \\
\hline Pessimistic & 17.3 & 17.2 & 19.7 & 21.5 & - \\
\hline High perceived vulnerability of weight gain (\%) & 36.4 & 30.0 & 29.6 & 31.9 & - \\
\hline High perceived severity of weight gain (\%) & 78.6 & 75.7 & 80.9 & 79.9 & - \\
\hline Motivation to prevent weight gain (PAPM) (\%) & 74.9 & 73.4 & 80.1 & 80.5 & $4>2$ \\
\hline BMI $\left(\mathrm{kg} \mathrm{m}^{-2}\right)$, mean (SD) & $23.9(2.58)$ & $23.6(2.60)$ & $24.0(2.83)$ & $23.7(2.58)$ & - \\
\hline Age (years) $†$, mean (SD) & $30.7(3.03)$ & $30.9(3.08)$ & $31.2(3.08)$ & $30.8(3.10)$ & $3>1$ \\
\hline Attitude towards weight-gain prevention $\ddagger$, mean (SD) & $0.62(0.63)$ & $0.56(0.66)$ & $0.69(0.63)$ & $0.65(0.60)$ & $3>2$ \\
\hline Overweight-related risk perception§, mean (SD) & $6.07(3.64)$ & $5.77(3.74)$ & $5.92(3.50)$ & $6.11(3.69)$ & - \\
\hline
\end{tabular}

BMI - body mass index; PAPM - Precaution Adoption Process Model; SD - standard deviation.

* Significant differences in gender, education, ethnicity, awareness and motivation to act were tested with the chi-square test. Differences in age and BMI were tested by analysis of variance. Differences in attitude and risk perception were tested with Mann-Whitney tests. Bonferonni adjustment was applied to all the analyses.

† Range 25-35 years.

$\ddagger$ Assessed with three items on a bipolar 5-point scale ranging from 'very bad/unimportant/unpleasant' (-2) to 'very good/important/pleasant' (+2). Item scores were summed and divided by three to obtain the mean attitude score.

$\S$ Assessed by asking the respondents how bad they would think it was if they gained weight on a 3-point scale ranging from 'not bad at all' (1) to 'very bad' (3). Perceived vulnerability was assessed by asking respondents whether they believed they were less or more at risk for weight gain compared with others of approximately the same age and height on a bipolar 5-point scale ranging from 'much less at risk' (1) to 'much more at risk' (5). Both item scores were multiplied to obtain the risk perception score (range 1-15). 
campaign recall and $21.4 \%$ versus $27.5 \%$ reported campaign recognition. Among these respondents, about a third knew the campaign from television, but only about $20 \%$ in the first post-test were familiar with one or more of the specific campaign activities such as the radio commercial, text messaging, brochure and the Internet. The familiarity with specific campaign activities dropped to $10 \%$ in the second post-test. Nevertheless, a majority of the respondents aware of the campaign were able to recall one of the campaign messages of which the 'healthy eating' and 'watching weight in order to avoid weight gain' were most often mentioned (see Table 3).

People of Dutch origin were more likely to be aware of the campaign (odds ratio $(\mathrm{OR})=1.66,95 \%$ confidence interval $(\mathrm{CI})=1.09-2.54)$ and were more likely to recall one of the campaign messages (OR $=1.70$, 95\% $\mathrm{CI}=1.11-2.62)$ than people of foreign origin or older respondents. The associations with age were also significant, showing that younger respondents were more aware of the campaign and one of the campaign messages $(\mathrm{OR}=1.04,95 \% \mathrm{CI}=1.00-1.09$ and $\mathrm{OR}=1.05$, $95 \% \mathrm{CI}=1.01-1.10$, respectively). No significant differences in campaign awareness were found according to sex, education or BMI.

\section{The impact of the campaign}

The first campaign was not significantly associated with changes in awareness of personal body-weight status, weight-related risk perceptions or motivation to prevent weight gain (Table 4). However, it was associated with significantly more positive attitudes towards the prevention of weight gain and higher self-reported BMI.

Interaction analyses indicated that the campaign effects did not differ significantly among people who were overweight, women, lower educated and of non-Dutch

Table 3 Awareness of campaign activities and message recall of respondents who are familiar with the campaign in the post-tests $(n=614)$

\begin{tabular}{lcc}
\hline & \multicolumn{2}{c}{ Post-tests } \\
\cline { 2 - 3 } & $3(n=297)$ & $4(n=317)$ \\
\hline Where did you learn about the & & \\
$\quad$ campaign? \% $(n)$ & $36.7(109)$ & $34.4(109)$ \\
$\quad$ Television or radio programme & $18.9(56)$ & $10.0(32)$ \\
Radio commercial & $7.4(22)$ & $5.0(16)$ \\
Newspaper & $6.1(18)$ & $6.9(22)$ \\
Advertisements for the mobile & & \\
$\quad$ phone text messaging & $3.4(10)$ & $3.2(10)$ \\
Brochure & $3.0(9)$ & $1.6(5)$ \\
Website & $82.2(244)$ & $83.3(264)$ \\
What was the campaign about? & & \\
\% $(n)$ & $46.1(137)$ & $51.7(164)$ \\
Healthy eating & $32.7(97)$ & $30.9(98)$ \\
Watch your weight to avoid & & \\
$\quad$ weight gain & $21.9(65)$ & $23.7(75)$ \\
$\quad$ Being active & $9.1(27)$ & $4.7(15)$ \\
Prevalence of obesity & $1.0(3)$ & 0 \\
Weight loss &
\end{tabular}

origin compared with normal-weight, male, higher educated and Dutch-origin respondents.

\section{Discussion}

This study evaluated the first phase of the mass media campaign entitled 'Maak je Niet Dik!' We found that the majority of the respondents knew about the first campaign, which was mainly due to the free publicity the campaign received, especially on national television and radio. Half of the study population was able to recall at least one campaign message. In addition, the campaign was associated with a more positive attitude towards the prevention of weight gain and a higher self-reported BMI, but no effects on awareness of personal body weight, overweight-related risk perception and motivation to prevent weight gain were found.

The fact that only moderate effects were detected, despite the rather high campaign awareness, may be due to the design and measures used for the evaluation study as well as the campaign itself. Since the campaign was launched nationally, it was not possible to include a control group in this study. In order to strengthen the basis for observing associations between the campaign and the indicators of the effects, we conducted repeated pre- and post-campaign surveys. This design provides stronger evidence for the impact of the campaign than evaluations that use only single 'before and after' surveys or studies in which only post-intervention data are collected ${ }^{29,30}$. Our second post-test was 7 weeks after the intervention and our study design therefore does not provide information on sustained effects. Longer-term effects of a short, concentrated mass media campaign are, however, not to be expected. Therefore, the present campaign will be continued in the years to come.

The use of self-reports was another limitation, as this study design did not allow the use of objective effect measures. The use of self-reported weight and height tends to result in some under- and overestimation of BMI. However, underestimation has been found to be limited in non-obese subjects ${ }^{31,32}$. The self-reported measures of attitudes and motivation may be biased because of social desirability. Finally, the external validity of the results may be limited because the response rate for the survey was about $70 \%$. Nevertheless, the samples of the different surveys did not differ in sociodemographic characteristics, and the sociodemographic characteristics of the samples were comparable to the census data of this population group, with the exception of ethnicity. Compared with census data, the present study included a somewhat higher percentage of people of Dutch origin ${ }^{33,34}$.

The high levels of campaign awareness were comparable to those found in other studies that used so-called 'small mass media', such as radio commercials, brochures and other promotion materials $20,35,36$. The present study shows that campaign awareness and message recall were 
Table 4 Results from logistic and linear regression analyses to assess the impact of time and campaign on campaign effect indicators ${ }^{*}(n=1949)$

\begin{tabular}{|c|c|c|c|c|}
\hline & \multicolumn{2}{|c|}{$\begin{array}{l}\text { Secular time } \\
\text { trend }(1-18 \text { weeks })\end{array}$} & \multicolumn{2}{|c|}{ Campaign $(0-1)$} \\
\hline & OR & $P$-value & OR & $P$-value \\
\hline $\begin{array}{l}\text { Awareness of personal body weight status } \\
(0=\text { bias; } 1=\text { correct })\end{array}$ & 0.98 & 0.30 & 1.08 & 0.77 \\
\hline \multirow{2}{*}{$\begin{array}{l}\text { Motivation to prevent weight gain } \\
(0=\text { no; } 1=\text { yes })\end{array}$} & 0.99 & 0.66 & 1.44 & 0.19 \\
\hline & $\beta$ & $P$-value & $\beta$ & $P$-value \\
\hline Attitude & -0.10 & 0.08 & 0.16 & 0.007 \\
\hline Risk perception & 0.00 & 0.97 & 0.01 & 0.88 \\
\hline BMI & -0.13 & 0.03 & 0.14 & 0.017 \\
\hline
\end{tabular}

OR - odds ratio; $\beta$ - standardised regression coefficient; BMI - body mass index.

${ }^{*}$ Analyses are corrected for age differences between the independent samples.

significantly lower in ethnic minority groups and older respondents within the studied age range. Message recall of the BBC's 'Fighting Fat, Fighting Fit' campaign was significantly poorer in those with lower levels of education and from ethnic minority groups in another study ${ }^{35}$. In contrast to that study however, the present study did not show that campaign awareness and message recall were lower in lower educated respondents. This may be because the 'Maak je Niet Dik!' campaign created much free publicity via popular television shows that draw large audiences, including lower educated people, and television as a medium for health communication has been found to be better accessible to less-educated groups than other media ${ }^{37,38}$

The first campaign phase was aimed at agenda-setting and creating awareness of a need to act (i.e. change) to prevent weight gain. The fact that during and soon after the campaign period, several national television and radio programmes and a significant amount of national newspaper articles on the issue were published may indicate that the campaign was successful in placing this issue of prevention of weight gain on the public agenda ${ }^{39}$. However, the results of our study show that despite the high levels of free publicity and campaign exposure, the campaign was not strong enough to provoke substantial changes in important predictors of behaviour change. Although the original campaign materials were carefully developed and pre-tested to make people aware of their own body-weight status, and to induce more positive attitudes and intentions towards prevention of weight gain, the free publicity the campaign created did not necessarily use the original campaign messages and contents. The free publicity was more focused on the prevalence of overweight and its health problems, rather than on the possibilities and urgency for the prevention of weight gain.

A remarkable result of this study was that the campaign activities were associated with an increase in reported BMI. This could indicate that the campaign may have led people to check their weights, resulting in more realistic BMI selfreports and possibly in increased awareness of the gradual process of weight gain. However, the present study did not show that such assumed more frequent checking of body weight produced more realistic evaluations of personal body-weight status or risk perceptions. This might be due to already high baseline levels on these variables. Furthermore, more accurate BMI self-reports do not, of course, automatically lead to increased levels of awareness of personal body-weight status.

The increase in self-reported BMI may also rely on the fact that the campaign was conducted in a period that included the Christmas and New Year's Eve holidays. As in most Western countries, these events are celebrated with consumption of high-calorie food. The campaign may also have made people more aware of their likely holiday-induced weight gain, leading to higher BMI selfreports ${ }^{40}$.

Our study indicates that a rather high proportion of the target population was already aware of their body weight, motivated to prevent weight gain, aware of the severity of overweight and obesity, and reported they watched their weight to avoid weight gain ${ }^{41}$. However, most respondents reported that they did not perceive a personal susceptibility to gain weight and may therefore not experience a personal need to change. Further, although most respondents reported having tried to avoid weight gain, Dutch data on trends in BMI indicate that most people in this age group are not successful in their attempts ${ }^{1}$. Thus further campaigns should aim at people's awareness of their personal susceptibility for weight gain and at communication of effective weight-maintenance practices. Additionally, there is some evidence that people from ethnic minority groups in The Netherlands may be less concerned about being overweight and may experience being overweight as more desirable ${ }^{42}$. Since ethnic minority groups may have profited least from the campaign, this group may require specific attention in future efforts. 


\section{Acknowledgement}

This research was supported by a grant from the Netherlands Nutrition Centre Foundation.

\section{References}

1 Seidell JC. Prevalence and time trends of obesity in Europe. Journal of Endocrinological Investigation 2002; 25(10): 816-22.

2 Visscher TLS, Kromhout D, Seidell JC. Long-term and recent time trends in the prevalence of obesity among Dutch men and women. International Journal of Obesity and Related Metabolic Disorders 2002; 26(9): 1218-24.

3 Visscher TLS, Seidell JC. The public health impact of obesity. Annual Review of Public Health 2001; 22: 355-75.

4 Mokdad AH, Ford ES, Bowman BA, Dietz WH, Vinicor F, Bales VS, et al. Prevalence of obesity, diabetes, and obesityrelated health risk factors, 2001. Journal of the American Medical Association 2003; 289(1): 76-9.

5 Peeters A, Barendregt JJ, Willekens F, Mackenbach JP, Al Mamun A, Bonneux L. Obesity in adulthood and its consequences for life expectancy: a life-table analysis. Annals of Internal Medicine 2003; 138(1): 24-32.

6 Seidell JC. The impact of obesity on health status - some implications for health care costs. International Journal of Obesity and Related Metabolic Disorders 1995; 19(Suppl. 6): S13-6.

7 World Health Organization (WHO). Obesity: Preventing and Managing the Global Epidemic. Technical Report Series No. 894. Geneva: WHO, 2000.

8 Hill JO, Wyatt HR, Reed GW, Peters JC. Obesity and the environment: where do we go from here? Science 2003; 299(5608): 853-5.

9 Blokstra A, Burns CM, Seidell JC. Perception of weight status and dieting behaviour in Dutch men and women. International Journal of Obesity and Related Metabolic Disorders 1999; 23(1): 7-17.

10 Wardle J, Johnson F. Weight and dieting: examining levels of weight concern in British adults. International Journal of Obesity and Related Metabolic Disorders 2002; 26(8): 1144-9.

11 Lechner L, Brug J, De Vries H, Van Assema P, Mudde A. Stages of change for fruit, vegetable and fat intake: consequences of misconception. Health Education Research 1998; 13(1): 1-11.

12 Ronda G, Van Assema P, Brug J. Stages of change, psychological factors and awareness of physical activity levels in The Netherlands. Health Promotion International 2001; 16(4): 305-14.

13 Ball K, Brown W, Crawford D. Who does not gain weight? Prevalence and predictors of weight maintenance in young women. International Journal of Obesity and Related Metabolic Disorders 2002; 26(12): 1570-8.

14 Ziebland S, Robertson J, Jay J, Neil A. Body image and weight change in middle age: a qualitative study. International Journal of Obesity and Related Metabolic Disorders 2002; 26(8): 1083-91.

15 Ball K, Crawford D, Ireland P, Hodge A. Patterns and demographic predictors of 5-year weight change in a multiethnic cohort of men and women in Australia. Public Health Nutrition 2003; 6(3): 269-81

16 Williamson DF. Descriptive epidemiology of body-weight and weight change in United-States adults. Annals of Internal Medicine 1993; 119(7): 646-9.

17 Noel PH, Pugh JA. Management of overweight and obese adults. British Medical Journal 2002; 325(7367): 757-61.
18 Glenny AM, O'Meara S, Melville A, Sheldon TA, Wilson C. The treatment and prevention of obesity: a systematic review of the literature. International Journal of Obesity and Related Metabolic Disorders 1997; 21(9): 715-37.

19 Randolph W, Viswanath K. Lessons learned from public health mass media campaigns: marketing health in a crowded media world. Annual Review of Public Health 2004; 25: 419-37.

20 Marcus BH, Owen N, Forsyth LH, Cavill NA, Fridinger F. Physical activity interventions using mass media, print media, and information technology. American Journal of Preventive Medicine 1998; 15(4): 362-78.

21 Flay BR, Burton D. Effective mass communication strategies for health campaigns. In: Mass Communication and Public Health: Complexities and Conflicts. London: Sage, 1990; 112-49.

22 Reid D. How effective is health education via mass communications? Health Education Journal 1996; 55 : $332-44$.

23 Finnegan JR Jr, Viswanath K, Hertog J. Mass media, secular trends, and the future of cardiovascular disease health promotion: an interpretive analysis. Preventive Medicine 1999; 29(6 Pt 2): S50-8.

24 Redman S, Spencer A, Sanson-Fisher RW. The role of mass media in changing health-related behaviour: a critical appraisal of two models. Health Promotion International 1990; 5(1): 85-101.

25 Cavill N, Bauman A. Changing the way people think about health-enhancing physical activity: do mass media campaigns have a role? Journal of Sports Science 2004; 22(8): 771-90.

26 Brug J, Kremers PJ, Wammes BM, Oenema A. Correlates of awareness of personal weight status. Submitted for publication.

27 Connor M, Norman P. Predicting Health Behaviour. Philadelphia, PA: Open University Press, 1995.

28 Weinstein ND, Sandman PM. A model of the precaution adoption process: evidence from home radon testing. Health Psychology 1992; 11(3): 170-80.

29 Nutbeam D. Evaluating health promotion - progress, problems and solutions. Health Promotion International 1998; 13(1): 27-44

30 Wellings K, Macdowall W. Evaluating mass media approaches to health promotion: a review of methods. Health Education 2000; 100(1): 23-32.

31 Rowland ML. Self-reported weight and height. American Journal of Clinical Nutrition 1990; 52(6): 1125-33.

32 Jeffery RW. Bias in reported body weight as a function of education, occupation, health and weight concern. Addictive Behaviors 1996; 21(2): 217-22.

33 Centraal Bureau voor de Statistiek (CBS). Statistisch Jaarboek. Voorburg: CBS, 2002.

34 Sociaal en Cultureel Planbureau (SCP). De Sociale Staat van Nederland 2003. Den Haag: SCP, 2003.

35 Wardle J, Rapoport L, Miles A, Afuape T, Duman M. Mass education for obesity prevention: the penetration of the BBC's 'Fighting Fat, Fighting Fit' campaign. Health Education Research 2001; 16(3): 343-55.

36 Van der Feen de Lille JC, Riedstra M, Hardeman W, Wedel M, Brug J, Pruyn JF, et al. Fat Watch: a nationwide campaign in The Netherlands to reduce fat intake - process evaluations. Nutrition and Health 1998; 12(2): 107-17.

37 Macaskill P, Pierce JP, Simpson JM, Lyle DM. Mass media-led antismoking campaign can remove the education gap in quitting behavior. American Journal of Public Health 1992; 82(1): 96-8.

38 Silver FL, Rubini F, Black D, Hodgson CS. Advertising strategies to increase public knowledge of the warning signs of stroke. Stroke 2003; 34(8): 1965-8. 
39 Samuels SE. Project LEAN - lessons learned from a national social marketing campaign. Public Health Reports 1993; 108(1): 45-53.

40 Yanovski JA, Yanovski SZ, Sovik KN, Nguyen TT, O'Neil PM, Sebring NG. A prospective study of holiday weight gain. New England Journal of Medicine 2000; 342(12): $861-7$.
41 Wammes B, Kremers S, Breedveld B, Brug J. Correlates of motivation to prevent weight gain: a cross sectional survey. International Journal of Behavioral Nutrition and Physical Activity 2005; 2: 1-8.

42 Mokhtar N, Elati J, Chabir R, Bour A, Elkari K, Schlossman $\mathrm{NP}$, et al. Diet culture and obesity in northern Africa. Journal of Nutrition 2001; 131(3): 887S-92S. 